\title{
Is nursing any business of doctors? A simple guide to the "nursing process"
}

\author{
J R A MITCHELL
}

It is obvious that what I have done could not have been done had I not worked with the medical authorities and not in rivalry with them.

FLORENCE NIGHTINGALE, to Sidney Herbert, $1855^{1}$

No man, not even a doctor, ever gives any other definition of what a nurse should be than this-"devoted and obedient." This definition would do just as well for a porter. It might even do for a horse. It seems a commonly received idea ... among women themselves that it requires nothing but a disappointment in love or an incapacity in other things, to turn a woman into a good nurse.

FLORENCE NIGHTINGALE in Notes on Nursing $1859^{2}$

The relation between doctors and nurses, and the nature of nursing itself were key issues in Florence Nightingale's struggle to create a nursing profession. During the intervening 130 years we have seldom been forced to re-examine these crucial questions, and have taken the nature of nursing and the doctor-nurse relationship for granted. We can do so no longer, for the advent of an American import in the shape of the "nursing process" will give us all the opportunity, if we are prepared to take it, to re-examine the two areas that Florence Nightingale perceived to be contentious issues-what are nurses and how should they relate to doctors? I would urge that the nursing process should not be adopted blindly by its proponents as a substitute for the dialogue that must occur sooner or later on these crucial questions. I hope that we can regard it as a catalyst rather than as a fait accompli which we have to learn to live with.

In dialectical terms I propose to regard the emergence of the nursing process as a thesis which can then provoke an antithesis. After informed debate it should then result in an acceptable synthesis. Unhappily, the reaction has already burst into the medical and nursing press ${ }^{3}$ before many readers will have been aware of the action that gave rise to it. This has puzzled many nurses, who cannot understand why the apparent acquiescence of their medical colleagues has suddenly given rise to violent opposition. The answer is simple-namely, that where such matters have been discussed doctors have heard the words "nursing process" and have falsely assumed that they related to the "processes of nursing" with which they have become familiar. My first task is to examine the vital differences between these deceptively similar phrases.

\section{Simple guide to the nursing process}

In 1967 a group of nurses in Washington DC set out a systematic method for identifying patient's problems, developing plans to resolve them, implementing the plans, and evaluating

Department of Medicine, University Hospital, Nottingham I R A MITCHELL, MD, FRCP, foundation professor of medicine whether they had been effective. ${ }^{4}$ In essence, this is the idea behind the nursing process, but because conditions are so very different in the United States, we need to turn immediately to the way in which this process has been taken up by the nursing profession in the United Kingdom. I shall take as my British guide to the "practice of nursing using the nursing process" a textbook of that name provided by the Manchester schools (one of the few academic centres of nursing in Britain).

\section{THE NATURE OF NURSING}

This is set out in 12 statements, of which perhaps the most crucial is that, "Nursing has to do with meeting the deficiencies of people in carrying out daily living activities (DLA), ie with deficits in self-care ability." In this respect, "The nurse is the authority on the maintenance of daily living activities while the doctor is, for instance, the authority on the diagnosis and treatment of disease. The roles are complementary and so closely related as to prohibit an adversarial relationship." In my view, all of the problems we shall soon encounter stem from this naive belief; as Herman Bondi once explained, "If I find that one of my students has reached an answer with which I disagree I never look at his mathematics. His arithmetic is always right so I look at the assumptions which precede equation one."

The fundamental error is to presuppose that problems of daily living activities can be separated from diagnosis and treatment. Thus, the needs of a patient with hemiplegia will be different if the weakness is transient (say after a fit or a minor embolus), permanent (after a completed stroke), or progressive (stemming from a brain tumour). Knowledge of the cause and clinical course of disease must thus precede any plans to remedy the resulting deficiencies of living activities. Moreover, the nurse is not the only authority on problems of daily living activity as physiotherapists, occupational therapists, chiropodists, dietitians, and appliance officers have a part to play, and someone must coordinate these activities and be responsible for their outcome.

\section{THE PROCESS ITSELF}

This begins with data collection, then assessment, planning, implementation, and evaluation.

Data collection begins with a "nursing history of physical, psychological, and social functioning" followed by "a head to toe systematic examination of the patient to determine any existing or potential problem areas" and "taking no longer than 20-30 minutes." Readers may wonder how these activities will fit in with the need for the medical staff to collect some data for themselves which bear immediately and directly on life saving and distress relieving treatments rather than on subsequent problems of daily living activity. Indeed the Manchester text 
seems to have forgotten about doctors by the time it gets to its 20th page, suggesting that to facilitate the task of the nurse processor, "communications may be with the patient himself, his family or friends and with other health professionals." Only 48 pages later does a more practical note creep in when it suggests that "valuable time can be saved by interviewing, and examining the patient at the same time as the doctor." Quite so, and isn't that what used to happen before the nursing process was discovered?

Assessment then follows, because the "nursing history is not an end in itself-it is a tool to elicit and record information so that problems can be identified and plans made to deal with them." At this point older medical readers may begin to experience a sense of déjà vu. Are we not up against problem orientated nursing records when many of us hoped that problem orientated medical records had gone the way of other crazes (like hula loops and skateboards)? If claims are to be made for problem orientated nursing records let us declare now that we must evaluate them properly in a way that was never undertaken for Laurence Weed's problem orientated medical records.

Next, our Manchester guides comment that "one of the major difficulties when it comes to stating a patient's nursing problems is that many nurses get confused with the patient's medical diagnosis" and worse is to come, in that "perhaps the only time when the patient's nursing problems are the same as his medical problems is in an emergency when the nurses' goals and actions are the same as the physicians'; for example in the case of cardiac arrest" (my italics). This seems to imply that in non-urgent situations the doctors' and nurses' goals must be different. I repudiate this doctrine and suggest that it gives the first clue to the rough ride which doctors are now giving the nursing process. An extension of this pernicious dichotomy between the "medical" and the "nursing" diagnoses is the hint that doctors are interested only in the disease and not in the person, whereas the nursing approach "treats him as an individual and identifies his problems." I believe that this perpetuates the medical stereotype which helped to promote the popularity of the Doctor in the House books but which is no longer true.

Having defined the problems, the nurse then prepares a plan for their resolution, identifies the people who will carry it out, and puts it into action. This may not require any departure from current practice, but suppose the nurse discovers a difficult social problem best referred to the trained social worker. Nurses are "to be encouraged to pass on information to others in the health-care team and act as co-ordinators of the patients' care" (my italics). There is a good deal of current discussion over the extended role of the nurse in such technical areas as cardiac defibrillation, and prostaglandin termination of pregnancy - no nurse is allowed to assume such an extended technical role without adequate training plus a certificate of competence from medical staff who are prepared to delegate such tasks to her. Should nurse-initiated referrals to other professionals, who might incidentally feel that their role was being altered (physiotherapists, occupational therapists, speech therapists, social workers, and dietitians), not be subject to similar scrutiny and agreement?

\section{Evaluation}

Never ask a barber if you need a haircut, and if the purpose of the nursing process is to improve patient care (and I believe that there may be an additional, hidden purpose) then the only way to evaluate it is to look at patient care and not to ask the providers of that care whether they approve of the new system. As doctors know only too well from our attempts to evaluate the best way to manage heart attacks, cancer, stroke, and high blood pressure, you get good answers only if you have well designed studies and suitable mathematical techniques. I know of no concerted plan to evaluate the effectiveness of the nursing process in Britain and $\bar{I}$ think that this is the second main reason for medical scepticism about its wholesale introduction. Our guiding text tells us that one evaluates by reassessing the patient and "comparing actual outcomes with expected outcomes." But suppose a patient with an apparent stroke is not able to walk by day 14, is this because the nursing plan was inappropriate or has not been properly carried out ? Alternatively, may it be because the patient has an irrecoverable stroke, a subdural haematoma, or a secondary cancer from a lung tumour? How can you determine expected outcome without considering the medical diagnosis and the known natural history of that disease?

There we have the nursing process in its skeletal form (data collection; assessment; planning; implementation; and evaluation), so having set out the thesis let us now examine the reactions that have resulted and that form the antithesis, before we try to produce a constructive synthesis.

\section{Reaction against the nursing process}

I believe that the areas of concern stem from the following doubts.

DOUBT ABOUT THE MOTIVATION OF ADVOCATES OF THE NURSING PROCESS

Clearly most nurses believe sincerely that the process could improve patient care, but I believe some nurses see it as a bid for independence from what they regard as medical domination. Many of the dilemmas in nursing are said' to stem from, "Their undefined role, a stunted initiative that comes from occupying a position subservient not only to the medical but to the paramedical professions, lack of real and appropriate authority and, above all, an ability to ensure the rights of patients by humane and enlightened care." The nursing process "would give nurses autonomy and to a considerable extent remove medical constraints." Even within this brief quotation we can detect a restatement of the unjustified smear that only nurses care about whole people, whereas doctors are simply interested in their diseases. Even in the official Royal College of Nursing guides to the process we read that "only professional nurses could set standards and assess and measure the quality of care given" " and "doctors and nurses must both recognise that their goals for a patient may differ or even conflict." 8

This formalises what many of us have felt anxious about for some time-namely, the progressive exclusion of doctors from nursing affairs. In many hospitals (but not, I am delighted to say, in my own) doctors have been removed from the appointment committees which choose ward sisters and nurse managers, and in many hospitals, including my own, have been virtually excluded from nurse teaching. The reason was not just financial (though doctors come dear), but a belief in "the natural emergence of nursing as a profession in its own right." In my view the background and training of the nurse teachers does not allow them to act as substitutes for doctors in the teaching about diagnosis and outcome. Moreover, teachers in clinical medicine continue to practise their medicine, surgery, obstetrics, or the like, whereas most nursing teachers have had to cease to be practising nurses. In many hospitals there is thus a considerable gap between what the ward sisters would like to see taught and what is actually taught in their nurse training schools.

In case readers feel that I am overstating this element of my case let me end by a quote from an internal commentator: "The fact that patients are admitted to hospital, generally by a doctor, does not give them any rights or control over the patient. It is purely the bureaucratic process that exists for gaining access to our health care system. ... What is wrong with a nurse deciding to admit a patient to hospital for nursing." "9 I fear that the writer is confusing rights with responsibilities and we shall return to this when we look at the legal implications of the nursing process. 
DOUBT ABOUT THE VALUE OF THE NURSING PROCESS

Many things have been foisted on medicine (units of medical time and the rigmarole of higher professional training) and on nursing (Salmon), which were never thought through before they were introduced on a national scale. If only hospitals could be encouraged (or indeed required) to build a mechanism for evaluation into their pilot schemes for the process, much of the criticism would melt away. It should be possible to design a variety of trials between and within hospitals that would resolve any doubts about the cost-benefit equations.

\section{DOUBT ABOUT THE DETAILS OF THE PROCESS ITSELF}

These centre around the following three areas:

fargon-I have used as my guide the clear and simple Manchester text, because many of the books from the United States have placed an impenetrable barrier of educational, sociological, and psychological jargon between them and their readers-referring, for example, to next of kin as significant others and meaningful persons.

Unnecessary complexity-One British text, ${ }^{10}$ which seeks to reassure its readers that "the model could be used in a variety of health care situations," provides a 12 page checklist "to help with collecting activities of living data." Information is sought on "maintaining a safe environment; communicating; breathing; eating and drinking; eliminating; personal cleansing and dressing; controlling body temperature; mobilising; working and playing; expressing sexuality; sleeping; dying." Each heading has a prompt list of some 40 to 50 items to be recorded, leading to the identification of the patients' problems, to the implementation of a nursing plan, and to evaluation. As an example let us consider "controlling body temperature." In my naive medical way I have always approached this problem by recording the body temperature but unhappily this is too simplistic. The checklist offers "measurement of body temperature-changes over time; relationships of ascertained temperature and changes to physiological, emotional, environmental, and socioeconomic factors. Indicators of an abnormally high temperature-flushed skin; increased sweating; increased pulse rate; decreased urine output; anorexia; disorientation. Indicators of an abnormally low temperature-pallor; shivering; decreased respiration rate/pulse/BP; lethargy; impairment of consciousness. Risk of developing hypothermia. Knowledge of causes/prevention/treatment of-pyrexia; heatstroke; hypothermia." The use of this bizarre list of symptoms and signs will confuse those nurses who manage to escape from their checklists and go to look at patients, for they will find that far from sweating and an increased pulse rate betokening anything to do with temperature homoeostasis they may actually be telling the observer that something is radically wrong with the circulation (bleeding; myocardial infarction; pulmonary embolus; septicaemia). They will also be puzzled to find that items from two of their lists which ought to be simultaneously indicating both high and low temperatures (pallor, sweating, disorientation, and loss of consciousness) might require that a diabetic receiving insulin should be given his lunch rather than have his temperature taken. In my view, such checklists should never have been compiled without adequate medical input; to attempt to construct them within an artificial framework of a "nursing diagnosis" is likely to impair patient care. This view is clearly shared by the general secretary of the Royal College of Nursing who challenges the idea that "the nursing process may have little to do with the medical diagnosis because it implies an altogether false dichotomy between the medical and nursing functions." "I wish he would remind his colleagues of this.

Time requirement-If the complex process forms I have collected from many parts of the country are to be properly completed, then desk work will consume an unwarranted proportion of the already limited time available to nurses for patient contact and practical nursing. I would wish nurses in training to be with patients as much as possible, talking to them, assessing their needs, and assisting them, rather than sitting at a desk completing checklists. I would sooner see the nurses at the bedside of acute stroke patients, dealing with their real needs and not working their way down a checklist ${ }^{10}$ on "expressing sexuality."

The failure of the documents on the nursing process to differentiate between the needs of patients with disabling chronic diseases such as rheumatoid arthritis, multiple sclerosis, or dementia, and of patients with acute life threatening problems such as bleeding, heart attack, and stroke must surely be corrected. If there is to be a nursing process, backed by documents, it must evolve upwards from patients' needs and not downwards from nursing schools. Such a development would produce documents that differed from specialty to specialty so that one would have different processes for acute medicine, acute surgery, paediatrics, and obstetrics, and others for geriatrics, mental illness, and handicap. There can surely never be a nursing process if the patient rather than the system is to be paramount, so we must now begin to plan for the "processes of nursing" rather than the "nursing process."

\section{DOUBT AS TO WHO NEEDS TO KNOW WHAT}

The entirely praiseworthy objective of the process was to make nursing care patient orientated rather than task orientated. The old nursing model was that one person "did the TPRs" while another "did the backs" whereas the idea behind the nursing process is that a group of nurses could be totally responsible for, say, six patients. If this can provide better total care for those patients I am in favour of it-but if nurses on acute wards are also to be expected to go through the long checklists then I am opposed. The present $37 \frac{1}{2}$ hour week does not allow the nurses who preside over the patient's admission to be available during the critical phases of his subsequent progress. On the average acute medical ward a patient may well have gone home by the time the original nursing team is back on duty, so do their successors need to start again with their own checklists or will they know about their patients only through the unnecessarily complex documents left by the admitting shift? Medical care is not yet organised on a shift basis-so the real continuity would still be provided by those very people who are not supposed to be interested in whole patients but only in their diseased parts.

Should not continuity, and thus the need for totality of knowledge, be built up with increasing seniority in nursing ? If ward sisters and their senior deputies could be detached from the present ritual of "earlies" and "lates" and work a normal day, would this not ensure that the person who does indeed need all the information in the checklists is available on the ward when managerial decisions about patient care are being taken? Would the introduction of different hours for senior nurses and of total internal night duty arrangements within a ward not do more for continuity of care than the nursing process ? Would it not be more sensible to build up a pyramid of knowledge so that new learners could concentrate on basic patient care rather than on checklists while their more clinically experienced colleagues could gradually begin to acquire a broader picture of patients' needs, using a simplified variant of the lists already described ? $^{5} 11$

\section{Synthesis}

As an aid to further discussion I offer the following propositions:

Doctors do care about nursing and would want to be actively involved in those aspects to which they can contribute. This should involve their reintroduction into nurse education and their introduction into the nursing process. Apparent medical 
indifference or acceptance does not mean that they are not interested but simply that they have never been asked and that they have never been told what the nursing process is.

Nothing should be introduced without built-in evaluation-Only half a century ago, medicine was a literate but not a numerate profession and many of the confident statements in our books and papers of the day were no more soundly based than the present claim that the nursing process will improve patient care. Before any further steps are taken to introduce the nursing process, its advocates must set down very simply the ways in which they believe that patient care and wcll being will be improved. We must then measure these indices before and after the process or on wards that do or do not adopt it. Until there has been adequate evaluation, the successor body to the General Nursing Council (the United Kingdom Central Council) should refrain from seeking to impose the nursing process on reluctant institutions by threatening to withhold their training recognition.

Anything that takes nurses away from patients is to be deploredThe spectacle of a row of nurses beavering away at complex and irrelevant checklists fills me with gloom; the documents should be the servant of nursing care and not its master.

Patient care cannot be done by committee, and responsibilities rather than rights should guide us-At present, the legal buck stops with the consultant or principal in general practice to whose care the patient has been entrusted. Employing authorities are alarmed at the suggestion that patients on a ward may be admitted by nurses, without being under the care of a doctor, or that there may be nursing documents, subserving a nursing diagnosis and a nursing plan, which are independent from or even in opposition to the medical diagnosis and the medical plan. I do not believe that two people can be equally in charge of one patient.

\section{Quo Vadis?}

I hope that nursing and medicine can devise a synthesis which will address itself to the two key questions that Florence Nightingale identified-what is a nurse ? and how should nurses and doctors work together in the provision of patient care? "No taxation without representation" was a rallying cry for our forefathers and I hope that my readers now see the need to become familiar with the nursing process so that they can join in an informed debate about it under the banner of "No introduction without discussion and evaluation." I am delighted to find that this is not just a personal or a medical view but is being actively supported by the nurses themselves" : "We should get our own act together in terms of the nursing process and start looking at what this type of approach really means to us and how it can help our professional practices and our patients. We should no longer pay lip service to the idea or hide behind a mountain of history sheets, nursing care plans, and other forms of communication. Unless we can come to terms with the commonsense principles of the nursing process approach and show in practical terms that we understand it ourselves, we are never going to have any success in describing to others how we, as nurses, contribute to the overall care of patients."

\section{References}

1 Woodham-Smith C. Florence Nightingale 1820-1910. London: The Reprint Society, 1952:153.

2 Woodham-Smith C. Florence Nightingale 1820-1910. London: The Reprint Society, 1952:271.

${ }^{3}$ Anonymous. Nursing process criticised. $\mathrm{Br} M e d \mathcal{f} 1983 ; 287: 439,441$.

4 Yura H, Walsh M. The nursing process. New York: Appleton-CenturyCrofts, 1978.

${ }^{5}$ Baroness Macfarlane of Llandaff, Castledine G. A guide to the practice of nursing using the nursing process. London: C V Mosby, 1982.

6 Bowman MP. Nursing by lamplight. The Health Services 1983;46:10-11.

7 Royal College of Nursing of the United Kingdom. Standards of nursing care. London: Royal College of Nursing, 1980.

${ }^{8}$ Royal College of Nursing of the United Kingdom. Towards standards. London: Royal College of Nursing, 1981.

${ }^{9}$ Ride T. Do we understand the process? Nursing Mirror 1983;Aug 17: 12-13.

${ }^{10}$ Roper N, Logan WW, Tierney AJ. Using a model for nursing. Edinburgh: Churchill-Livingstone, 1983.

11 Clay T. Nurses are not doctors. The Health Services 1983;47:7.

(Accepted 19 September 1983)

\author{
RAY ROWDEN
}

The history and development of nursing require examination. The popular image of nurses as compliant and devoted flows from the misconceptions held about the history of the profession. People are inclined to rely on the work of Florence Nightingale and presume that her model for nursing is sacrosanct, but traditional images are now being challenged. ${ }^{1}$ Contrary to popular belief, Florence Nightingale did not have things all her own way. She felt that the probationer nurse could survive on six months of training and needed to be solidly built. Ethel Bedford Fenwick, a doctor's wife, had different views and saw the need for an academic training for the nurse practitioner;

\section{Royal Marsden Hospital, London SW3}

RAY ROWDEN, SRN, RMN, director of nursing services

Correspondence to: Royal Marsden Hospital, Downs Road, Sutton, Surrey SM2 5PT. much of her work was to influence the shape of the first piece of legislation for nurses in $1919 .{ }^{2}$ Both women had groups of supporters and each group argued its case, often vitriolically. An understanding of the history of the profession is important in relation to changes in patterns of nursing care.

At the Royal Marsden Hospital we use the nursing process in all wards and have done so for a number of years. I would like to share some of the thinking behind our approach to care and some of our experiences.

\section{The nature of nursing}

The nursing and medical professions are totally interdependent, it is therefore essential that we learn to share major issues, establish dialogue, and learn to accommodate each other maturely. The demands placed on the nurse today are radically different from those of 20 years ago. The nurse needs to have 